\title{
Decoupled evolution of mating biology and social structure in Acromyrmex leaf-cutting ants
}

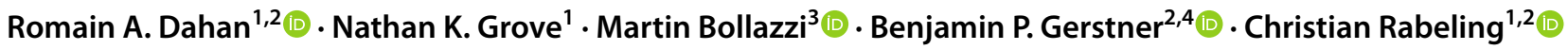

Received: 16 August 2021 / Revised: 15 November 2021 / Accepted: 3 December 2021 / Published online: 30 December 2021

(c) The Author(s) 2021

\begin{abstract}
Insect societies vary greatly in their social structure, mating biology, and life history. Polygyny, the presence of multiple reproductive queens in a single colony, and polyandry, multiple mating by females, both increase the genetic variability in colonies of eusocial organisms, resulting in potential reproductive conflicts. The co-occurrence of polygyny and polyandry in a single species is rarely observed across eusocial insects, and these traits have been found to be negatively correlated in ants. Acromyrmex leaf-cutting ants are well-suited for investigating the evolution of complex mating strategies because both polygyny and polyandry co-occur in this genus. We used microsatellite markers and parentage inference in five South American Acromyrmex species to study how different selective pressures influence the evolution of polygyny and polyandry. We show that Acromyrmex species exhibit independent variation in mating biology and social structure, and polygyny and polyandry are not necessarily negatively correlated within genera. One species, Acromyrmex lobicornis, displays a significantly lower mating frequency compared to others, while another species, A. lundii, appears to have reverted to obligate monogyny. These variations appear to have a small impact on average intra-colonial relatedness, although the biological significance of such a small effect size is unclear. All species show significant reproductive skew between patrilines, but there was no significant difference in reproductive skew between any of the sampled species. We find that the evolution of social structure and mating biology appear to follow independent evolutionary trajectories in different species. Finally, we discuss the evolutionary implications that mating biology and social structure have on life history evolution in Acromyrmex leaf-cutting ants.
\end{abstract}

\section{Significance statement}

Many species of eusocial insects have colonies with multiple queens (polygyny), or queens mating with multiple males (polyandry). Both behaviors generate potentially beneficial genetic diversity in ant colonies as well as reproductive conflict. The co-occurrence of both polygyny and polyandry in a single species is only known from few ant species. Leaf-cutting ants have both multi-queen colonies and multiply mated queens, providing a well-suited system for studying the co-evolutionary dynamics between mating behavior and genetic diversity in colonies of eusocial insects. We used microsatellite markers to infer the socio-reproductive behavior in five South American leaf-cutter ant species. We found that variation in genetic diversity in colonies was directly associated with the mating frequencies of queens, but not with the number of queens in a colony. We suggest that multi-queen nesting and mating frequency evolve independently of one another, indicating that behavioral and ecological factors other than genetic diversity contribute to the evolution of complex mating behaviors in leaf-cutting ants.

Keywords Attini $\cdot$ Fungus-growing ants $\cdot$ Polyandry $\cdot$ Polygyny $\cdot$ Social evolution $\cdot$ Social parasitism

\section{Introduction}

Communicated by A. Toth.

Extended author information available on the last page of the article
The evolution of mating behavior and reproductive biology is central to the evolution of complex animal societies (Clutton-Brock 1985; Bourke 2014). Extensive research has been conducted linking mating biology evolution and social 
evolution in mammals, birds, and arthropods (Rubenstein and Wrangham 1986), notably identifying trait associations involving life history, social organization, parental care, and mating systems (Maynard Smith 1977; Clutton-Brock 1985; Choe and Crespi 1997; Stanford 1998; Lukas and CluttonBrock 2012a). Mating systems in particular have been associated with cooperative breeding and social evolution in insects, birds, and mammals, and monogamy was identified as one important trait associated with the evolutionary origin of cooperative breeding in animal societies (Hughes et al. 2008a; Cornwallis et al. 2010; Lukas and Clutton-Brock 2012b).

The eusocial insects have been used as a model for studying the evolution of complex societies and cooperative breeding because of their complex social organization. Eusocial insects are characterized by overlapping generations, cooperative brood care, and an irreversible reproductive division of labor (West-Eberhard 1975; Wilson 1975). Lifetime monogamy is considered a precondition for the evolution of eusociality, as a strictly monogamous mating biology allows for maximum relatedness between individuals of the same colony (Hughes et al. 2008a; Boomsma 2009; Cornwallis et al. 2010; West and Gardner 2010; Lukas and Clutton-Brock 2012b). However, secondary deviations from lifetime monogamy have been observed in many eusocial insects. Interestingly, the evolution of mating biology appears asymmetric in different eusocial insect lineages. Polygyny, the presence of multiple egg-laying queens in a colony, has primarily been observed in ants and termites, but is only observed in a small proportion of social bees and wasps (Hartke and Baer 2011; Boomsma et al. 2014). In contrast, polyandry, multiple mating by females, has frequently been observed in honeybees, but is only known from few examples in ants and vespine wasps, and is virtually unknown from bumblebees, stingless bees, polistine wasps, and termites (Strassmann 2001; Hartke and Baer 2011). Only very few species, all of which are ants, are known to display both polygyny and polyandry simultaneously (Keller and Reeve 1994; Pedersen and Boomsma 1999a; SchmidHempel and Crozier 1999; Kellner et al. 2007).

The factors underlying the evolution of polygyny and polyandry in eusocial insects have been extensively debated. Many hypotheses have been proposed to explain both phenomena, particularly in eusocial Hymenoptera. Two main hypotheses for the evolution of polyandry in eusocial insects are widely accepted (Ratnieks and Boomsma 1995; Boomsma and Ratnieks 1996; Crozier and Fjerdingstad 2001; Strassmann 2001; Boomsma et al. 2009): (1) the sperm-limitation hypothesis posits that multiple mating events may be required for queens to acquire enough sperm to reproduce throughout their lifetimes (Fjerdingstad and Boomsma 1998; Kraus et al. 2004; Kronauer and Boomsma 2007). (2) The genetic-diversity hypothesis proposes that increased genetic variation within colonies is beneficial and adaptive due to an increased resistance of genetically variable colonies to pathogens and parasites (Kraus and Page Jr. 1988; Baer and Schmid-Hempel 1999; Seeley and Tarpy 2007), and/or higher colony productivity due to a more efficient partitioning of task specializations among workers, through genetic polyethism (Page et al. 1989; Crozier and Fjerdingstad 2001; Hughes et al. 2003; Julian and Fewell 2004; Oldroyd and Fewell 2007; Waddington et al. 2010).

On the other hand, the evolution of polygyny is addressed by two principal explanatory frameworks: (1) ecological factors, which associate high potential cost to dispersal and/or independent nest founding due to unfavorable environmental conditions, both biotic and abiotic (Bourke and Franks 1995). Newly mated females may be selected to attempt rejoining their natal colonies (or a nearby conspecific colony), resulting in secondary polygyny from queen adoption. Queen adoption is beneficial if the likelihood of successful dispersal and colony founding is low, under pressures such as competition for resources, low nest site availability (in the case of high population density), and high predation (Bourke and Franks 1995; Seppä et al. 1995; Banschbach and Herbers 1996; Pedersen and Boomsma 1999a; Ingram 2002; Purcell et al. 2015). Similarly, primary polygyny, resulting from the association of colony-founding queens, may result from ecological pressures where solitary colony foundation is unfavorable, and co-founding results in a higher probability of a successful colony being established (Cahan and Julian 1999; Haney and Fewell 2018). (2) Social/genetic factors may promote the evolution of polygyny (both primary and secondary) by allowing for, and sometimes promoting, the co-existence of queens in colonies. The proposed benefits are aligned with the genetic diversity benefits for the evolution of polyandry, including more efficient division of labor in a diverse workforce, greater resistance to disease and parasites, and overall more productive colonies (Bourke and Franks 1995; Keller 1995; Schmid-Hempel and Crozier 1999; Oldroyd and Fewell 2007).

The main difference of polygyny versus polyandry for intracolonial relatedness is that polygyny introduces more genetic variation into a colony compared to polyandry because females produced by a single, multiply mated queen are half siblings, with an minimum relatedness of 0.25 , while females produced by different unrelated mothers should not be more related than any two individuals from that population (i.e., they are only as related as the inbreeding coefficient in their population) (Pedersen and Boomsma 1999a). In some cases the increased genetic diversity introduced by polyandry is alleviated or cancelled out by inbreeding (Trontti et al. 2007), and by the fact that males mating with a single female are often related (Pedersen and Boomsma 1999b; Kellner et al. 2007). Similarly, relatedness between nestmate queens (for example, if nestmate queens are sisters 
or mother/daughters) would alleviate some of the negative effects of polygyny on relatedness. Empirical evidence has shown that experimentally combining workers from different colonies (which should then be as related as two workers produced by unrelated nestmate queens) increased disease resistance in socially polymorphic species across eusocial insects (Baer and Schmid-Hempel 1999; Tarpy 2003; Hughes and Boomsma 2004; Reber et al. 2008).

In contrast to these benefits of polygyny and polyandry, reduced colony relatedness also increases the potential for conflict in eusocial insect colonies. Nepotism (the preferential rearing of related brood by workers) is an expected consequence of multiple reproductive lineages coexisting in a colony. While it has not been demonstrated clearly in cases of polyandry (Page et al. 1989; Breed et al. 1994), empirical evidence has demonstrated occurrences of nepotism in polygynous species (Hannonen and Sundström 2003). While this phenomenon increases the inclusive fitness of nepotistic lineages, it may result in an overall reduction of colony productivity (Page et al. 1989).

Polygyny itself introduces conflict over reproduction between nestmate queens, particularly for the production of reproductive females (Reeve and Ratnieks 1993; Bourke and Franks 1995). In extreme cases, this conflict can result in the evolution of obligate inquiline social parasites, as has been documented for inquiline social parasites that originated as reproductive cheaters and speciated directly from their hosts (Savolainen and Vepsäläinen 2003; Rabeling et al. 2014b, 2018; Leppänen et al. 2015; Nehring et al. 2018). These obligately parasitic species are often workerless or nearlyworkerless, and "infiltrate" colonies of their hosts, taking advantage of host workers to rear their offspring (Buschinger 2009; Rabeling 2020). Secondary polygyny has been associated with the evolution of inquiline social parasitism, as it would not only provide an opportunity for socially parasitic nest foundation, but also provide the opportunity for reproductive cheating to appear and be accepted inside the host colony (Bourke \& Franks, 1991; Buschinger, 2009; Dahan \& Rabeling in Review).

Among ants, the colony and social structures of leafcutting ants are known to be particularly diverse (Boomsma et al. 1999), and five obligate social parasite species are known in Acromyrmex leaf-cutting ants and the monotypic social parasite genus Pseudoatta (Rabeling et al. 2019). Acromyrmex leaf-cutting ants are of particular interest for studying the evolution of mating behavior and life history traits (Hölldobler and Wilson 1990; Diehl-Fleig and de Araújo 1996; Boomsma et al. 1999; Villesen et al. 1999, 2002; Murakami et al. 2000; Diehl et al. 2001; Rabeling et al. 2015, 2019; Nehring et al. 2018). All free-living (i.e., non-socially parasitic) leaf-cutting ant species investigated so far, which includes at least seven Acromyrmex species, have been reported to be obligately polyandrous. In contrast, the queens of fungus-growing ants in distantly related genera outside the leaf-cutting ants are predominantly singly mated (Villesen et al. 1999, 2002). Additionally, some species of Acromyrmex (A. heyeri, A. echinatior, A. subterraneus bruneus, and A. subterraneus molestans), as well as Amoimyrmex striatus, are reported to be facultatively polygynous (Delabie 1989; Bekkevold et al. 1999; Diehl et al. 2001; Souza et al. 2004; Nehring et al. 2018), whereas others, such as A. landolti (Keller and Reeve 1994) and A. octospinosus (Boomsma et al. 1999), as well as most species of Atta are monogynous, with the exception of the primarily polygynous Atta texana (see Mintzer 1987). Therefore, Acromyrmex is one of the rare ant genera with different species exhibiting a mosaic of mating behaviors and social structures, which allows for comparative investigations of both the evolutionary causes and consequences of complex mating behaviors in eusocial Hymenoptera, especially with respect to the coevolution between multiple mating and polygyny, and its consequences on the evolution of life history traits in these species, such as the emergence of social parasitism. Here, we investigate the mating biology and population genetic colony structure of five South American Acromyrmex species. We conduct a comparative evolutionary analysis of mating biology and colony structure, and we provide an analysis of the co-evolutionary dynamics between polyandry and polygyny in Acromyrmex leaf-cutting ants.

\section{Methods}

\section{Species collection and sampling}

To study the mating biology and social structure in South American leaf-cutting ants, we investigated five species: Acromyrmex ambiguus, A. crassispinus, A. heyeri, A. lobicornis, and A. lundii. All but one of these species are known hosts of the obligate inquiline social parasites Pseudoatta argentina and $A$. charruanus, and the social structure and mating biology of these host species, except for A. heyeri, remain unknown so far (Gallardo 1916; Diehl et al. 2001; Rabeling et al. 2015). Acromyrmex lobicornis has not been observed to host a social parasite species, but it was inferred as the closest relative to a clade including three social parasite species (Rabeling et al. 2018). Therefore, the biology of both A. lobicornis and the known hosts is relevant for discussing the association between social structure and the evolution of social parasitism in leaf-cutting ants (Dahan \& Rabeling, in review). Workers, and when present, sexual reproductives (alates), of each species were collected from nests in their native ranges in Uruguay and Southern Brazil, between March 2012 and November 2013 (Fig. 1; Table S1). All samples were preserved in $100 \%$ ethanol and identified visually with a Leica M205 C stereomicroscope, 


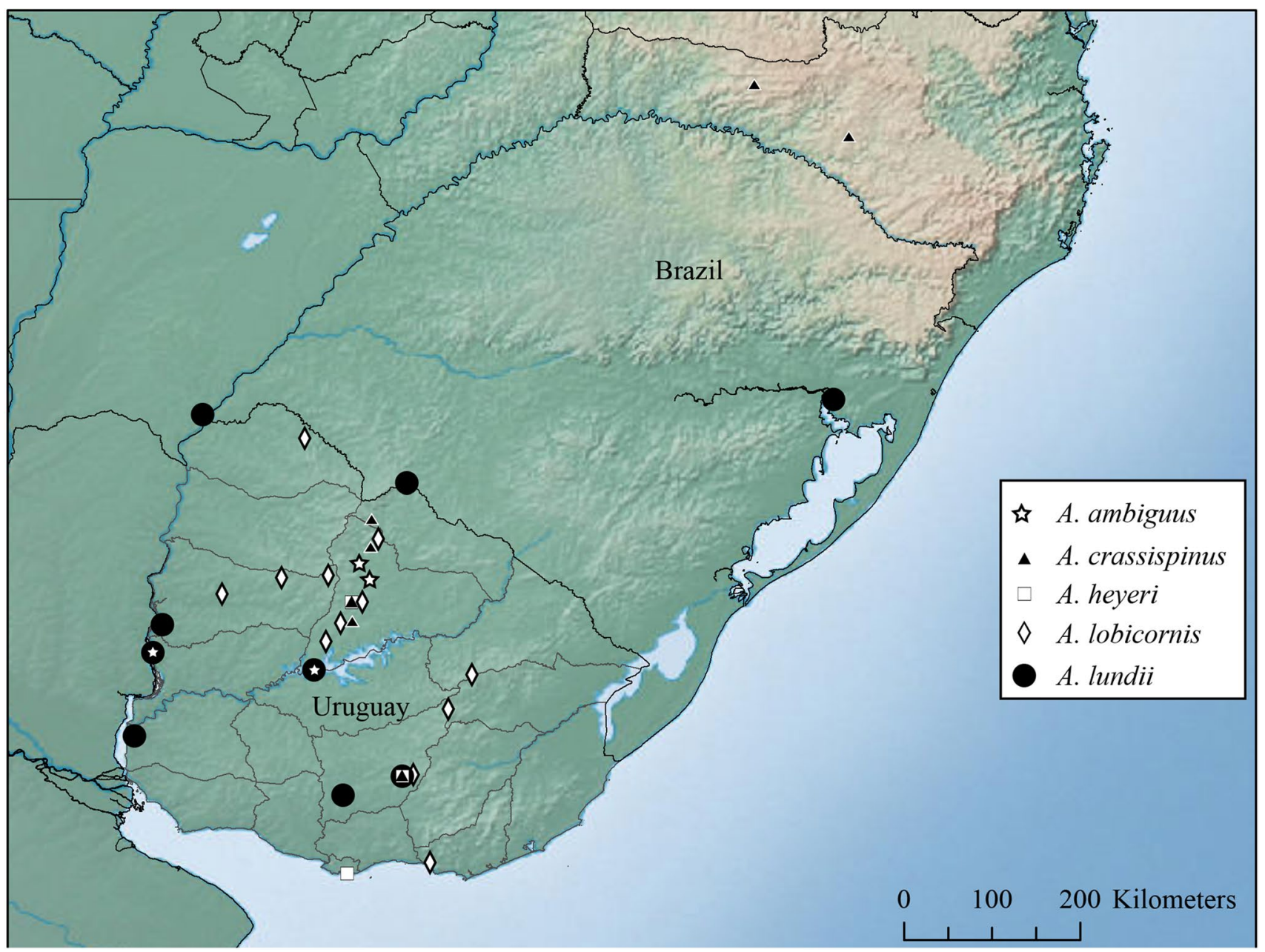

Fig. 1 Sampling map depicting field study sites where Acromyrmex colonies were collected

using published taxonomic keys (Gonçalves 1961; Fowler 1985, 1988). Voucher specimens were deposited in the Social Insect Biodiversity Repository (SIBR) at Arizona State University in Tempe, Arizona, and in the entomological collection of Martin Bollazzi's laboratory at the Facultad de Agronomía of the Universidad de la República in Montevideo, Uruguay.

\section{Microsatellite selection and colony genotyping}

To infer individual genotypes, six microsatellite loci were selected out of 22 loci characterized for A. lundii (Rabeling et al. 2014a), based on allele diversity and range overlap in each locus, to obtain the most informative sampling (Table S1). The selected markers were used in three duplex PCR reactions. For each screened colony, we sampled between 16 and 48 individuals, with a minimum of 16 workers and a maximum of 16 males. Colony samples were maximized based on field sampling, and a total of 89 colonies were analyzed for A. crassispinus $(n=18)$, A. heyeri $(n=25)$, A. lobicornis $(n=18)$, and A. lundii $(n=28)$. Additionally, we genotyped four colonies of the related species $A$. ambiguus, but additional sampling could not be completed (see SI). If sampling 48 individuals per colony was impossible, sampling was reduced by increments of 8 individuals, to a minimum of 16 workers. In all but two species, all genotypes available were from workers. For A. crassispinus, female alates were available in six colonies, in which we sampled 5-24 alates; in A. heyeri, both female and male alates were sampled from five colonies (8-12 female alates, 10-16 males). In total, 4,614 individuals were screened, generating 27,684 genotyped loci. DNA was purified using the Qiagen PureGene blood \& tissue kit. Markers were amplified in duplex PCR reactions, each containing 1-10 ng of template DNA. Genotyping was conducted at each locus by fragment analysis, and genotypes were visually scored against a Genescan LIZ-500 standard using 6-Fam and NED tagged primers (Applied Biosystems). All scoring of genotypes was conducted in Geneious 8.1.4 (Kearse et al. 2012), and all genotypes were scored blindly by a single 
observer (RAD) without knowledge of colony of origin of each samples.

\section{Inference of parental genotypes}

Parental genotypes were inferred for each colony, first by using the COLONY software package (Jones and Wang 2010), followed by manual resolution using the COLONY output as a starting point. The number of queens in a colony was inferred from the results of the parental inference. Offspring with three missing loci or more in the final dataset (i.e., loci that failed to amplify after at least two PCR attempts) were discarded. A high frequency of missing loci within colonies may be indicative of a high frequency of null alleles or undetectable mutations, which would introduce bias and error in our analyses. Thus, whole colonies where more than $25 \%$ of the offspring had two missing loci or more were excluded from further analyses. Whole colonies with more than $25 \%$ of discarded workers were also excluded. COLONY was run using entire species-specific datasets, updating the allele frequencies between each run. The software is equipped to handle such missing loci: the input allelic dropout rate, representing the frequency with which alleles change in offspring due to mutations, was set as $10^{-4}$, as this is the fast limit of microsatellite mutation rate observed in arthropods (Bhargava and Fuentes 2010). The genotyping error rate, accounting for extrinsic factors resulting in genotyping errors (null alleles, human error, etc.), was also set at $10^{-4}$ for each locus, as the default for the software. The results for each colony were then visually inspected to confirm the validity of the inferred maternal genotypes, and manually rechecked, correcting the inference to produce the most conservative estimate, and correcting any genotyping error. In many cases, several resolutions could account for the observed genotypes within a single colony. In these cases, resolutions were selected based on several criteria, in order of importance:

1. Parental inferences with the least number of queens (maternal genotypes) were favored;

2. If genotypes of multiple queens differed at a single locus within a colony, a single queen was inferred as mother of all the offspring of these queens, and the discordant offspring would be accounted for as genotyping error;

3. Inferences approaching a 1:1 Mendelian ratio for maternal alleles were favored (sensu Kronauer et al. 2004);

4. Inferences with the least number of sires (paternal genotypes) were favored;

5. Inferences minimizing the number of discarded individuals were favored;

6. Inferences minimizing the genotyping error rate were favored.
These criteria of selection ensured that the most conservative resolution was selected (i.e., resulting in the lowest possible number of queens and sires) for the genotypes obtained from a single colony. Due to our sampling and inference approach, it was possible to underestimate the number of queens and sires, but much less likely to overestimate these values. After manual resolution, maternal genotypes contributing less than four offspring (for $n=48$ ), or two offspring (for $n \leq 24$ ) were ignored and their offspring discarded. This threshold was selected not only to be able to calculate the Mendelian segregation ratios of queens, but also to minimize false positives (offspring clustering to an additional matriline due to mutation, migration from a neighboring colony, or genotyping error), while maintaining a high probability of sampling offspring of all queens in a colony, even with moderately high reproductive skew between queens (see SI).

\section{Inference of mating frequencies and intra-colonial relatedness}

The effective number of mates per queen was inferred using the formula

$m_{e}=\frac{(N-1)^{2}}{\sum p_{i}^{2}(N+1)(N-2)+3-N}$

where $N$ represents the total number of successfully assigned offspring, and $p_{i}$ represents the proportion of offspring produced by the $i$ th father (Nielsen et al. 2003). We then calculated inter-individual relatedness $(r)$ within all colonies following the Queller \& Goodnight method (Queller and Goodnight 1989). In order to avoid pseudoreplication, the average within-colony relatedness was calculated for each colony and considered in all statistical analyses.

\section{Reproductive skew}

We investigated reproductive skew (describing inter-individual differences in offspring production) between the different patrilines mated to each single queen, using the PamiloCrozier skew index (Pamilo and Crozier 1996). In all cases, only workers were used to determine reproductive skew. The index represents the deviation between the number of patrilines observed mated to a queen and the effective mating frequency of a queen, standardized to the maximum variance in offspring contribution:

$S=\frac{M-m_{e}}{M-1}$

Here, $M$ is the inferred number of males mated to a queen and $m_{e}$ is the effective mating frequency of that queen (see above). This index varies between 0 , representing no skew, 
with equal contribution between all sires mated to a queen, and 1 , representing a case where the reproductive skew is absolute and a single sire is producing all offspring. Note that the inference method presented here means that the value of $S$ can never be exactly 1 , since we are relying on patriline detection in the offspring generation to infer the males represented in the colony.

\section{Statistical analyses}

We investigated variation in observed mating frequency (number of males mated to each queen), effective mating frequency, reproductive skew, and average intra-colonial relatedness for all five species. Observed mating frequency, effective mating frequency, and skew index were compared between species using Kruskal-Wallis tests, performing post hoc pairwise Mann-Whitney $U$ tests where appropriate, applying a false discovery rate correction in all cases $(F D R=0.05)$. The response variables (number of mates, effective mating frequency, and reproductive skew) can be expected to violate assumptions of normality; therefore, nonparametric tests were favored. In order to assess the roles of effective mating frequency and social structure on average intra-colonial relatedness between species, a linear regression was fit across all species with relatedness as a response variable, and number of queens, effective mating frequency, and their interaction, as well as species, as predictor variables. Species was included as a predictor variable in order to account for any intrinsic between-species differences in relatedness. Effective mating frequency was log-transformed for this analysis. Assumptions of residual normality and homoscedasticity were met for the regression (Fig. S1). We excluded A. ambiguus from all interspecific analyses to avoid statistical issues involving low power and uneven sampling, as we were only able to analyze four colonies. For the intra-specific estimates of mating behavior, we chose to report the data for the four A. ambiguus colonies; however, these results should be viewed as preliminary. Within species, we compared both the average observed relatedness $(r)$ and the effective mating frequency between polygynous and monogynous colonies. Because of our sampling, these comparisons were only possible for A. heyeri and A. lobicornis. In these cases, we used Student's $t$-tests (with equal variance) to compare the groups, except to compare effective mating frequency in A. heyeri, where a Welch two-sample $t$-test was more appropriate to account for unequal variance. In all cases, we used the average value for each colony as a replicate within a group to avoid pseudoreplication (averaging the effective mating frequency of all queens in a colony for polygynous colonies). In all cases, we set the significance threshold at $\alpha=0.05$. All analyses were performed in $\mathrm{R}$
4.1.0, using the packages 'related' and 'ggplot2' (Wickham 2009; Pew et al. 2015; R Core Team 2021).

\section{Results}

\section{Social structure of Acromyrmex leaf-cutting ants}

We investigated the social structure of five South American species of Acromyrmex leaf-cutting ants based on 27,684 genotypes among six loci generated for 4,614 individuals. We detected different social structures and mating behaviors among these species. All 28 colonies of Acromyrmex lundii were inferred to be monogynous. In contrast, $A$. crassispinus ( $2 / 18$ polygynous; $11 \%)$, A. heyeri ( $5 / 25$ polygynous, $20 \%$ ), and A. lobicornis (5/18 polygynous; $28 \%$ ) were socially polymorphic, consisting of both monogynous and polygynous colonies (Table 1). Among the facultatively polygynous species, most polygynous colonies comprised two matrilines, with the exception of one colony of A. crassispinus in which three queens were inferred, and one colony of A. lobicornis in which four queens were inferred (Table 1). One out of four A. ambiguus colonies was polygynous with two matrilines, whereas the other three colonies were monogynous, suggesting that $A$. ambiguus is also facultatively polygynous.

\section{Multiple mating and effective mating frequency of Acromyrmex queens}

In all five species, queens used sperm from multiple males to produce offspring, although there were marked differences between species (Table 1; Kruskal-Wallis test: $\chi_{3}^{2}=21.66$, $p=7.67 \times 10^{-5}$ ). Specifically, the observed mating frequency (i.e., the actual number of detected males mated to a queen) of $A$. crassispinus queens (average observed mating frequency $M=6.48$ ) is higher than that of three of the other species, although it is statistically indistinguishable from that of $A$. heyeri queens ( $M=5.50$; Table 1; Fig. 2a). Conversely, queens of A. lobicornis are mated to significantly fewer males compared to the other species $(M=2.88)$. It is worth noting that queens of $A$. crassispinus and $A$. heyeri also mate with a higher maximum number of mates (max. 12 mates) compared to A. lobicornis (max. 4 mates) and $A$. lundii (max. 6 mates) (Table 1). Preliminary analysis suggests that queens of $A$. ambiguus mate with a high number of males ( $M=6.00$, max 10 mates), appearing comparable to queens of $A$. crassispinus and $A$. heyeri.

Interestingly, in spite of the higher observed mating frequency in A. crassispinus, this species had a similar effective mating frequency (i.e., the effective number of mates contributing to a queen's offspring) $\left(m_{e}=4.51\right)$ 
compared to A. heyeri $\left(m_{e}=4.43\right)$ and to A. lundii $\left(m_{e}=\right.$ 3.33; Table 1). Similar to the pattern seen for the observed mating frequency, the effective mating frequency of queens of A. lobicornis ( $\left.m_{e}=2.36\right)$ was significantly lower than in the other species (Kruskal-Wallis test: $\chi^{2}{ }_{3}=17.81$, $p=4.81 \times 10^{-4} ;$ Fig. $2 b$ ). In all cases, the observed number of mates was much lower than the number of sampled offspring, ensuring unbiased estimation of $m_{e}$ following the assumptions of the estimator (Nielsen et al. 2003). In A. ambiguus, the effective mating frequency of queens was comparatively high $\left(m_{e}=5.92\right)$.

\section{Reproductive skew}

We detected reproductive skew between patrilines in all species (Fig. 3). While the values recovered varied between $\sim 0.1$ and $\sim .45$ (a value of 0 indicates an equal reproductive share between males, whereas a value of 1 indicates that all offspring are sired by a single male), no significant differences were found between species (A. crassispinus: $S=0.41 ; A$. heyeri: $S=0.26$; A. lobicornis: $S=0.26$; . lundii $=0.26$; Kruskal-Wallis test: $\chi_{3}^{2}=6.82, p=0.08$; Table 1, Fig. 3 ).

\section{Intra-colonial relatedness}

Based on the multiple regression, we found no evidence for a significant difference in average intra-colonial relatedness between species (ANOVA: $\mathrm{F}_{2,72}=3.10, p=0.0513$; Table 1, Fig. 4). When scrutinizing the regression parameters, it appears that $A$. heyeri colonies show a slightly lower intra-colonial relatedness $\left(r \pm\right.$ std. error $=0.36 \pm 2.8 \times 10^{-2}$ ) compared to A. lundii $\left(r=0.46 \pm 2.6 \times 10^{-2}\right)$, A. crassispinus $\left(r=0.46 \pm 3.2 \times 10^{-2}\right)$, and $A$. lobicornis $\left(r=0.46 \pm 3.2 \times 10^{-2}\right)$. Effective mating frequency had a highly significant effect on intra-colonial relatedness (estimated regression parameter $b_{\text {mating }}=-0.234, \mathrm{~F}_{1,72}=44.61$, $p=4.86 \times 10^{-9}$; Fig. 4). We also found a significant difference in how effective mating frequency affected relatedness in monogynous vs. polygynous colonies $\left(F_{1,72}=4.054\right.$, $p=0.0478$; Fig. 4). On the other hand, social structure alone had no detectable effect on relatedness $\left(F_{1,72}=0.0193\right.$, $p=0.890$, Fig. 4). Relatedness in colonies of A. ambiguus appeared indistinguishable from that inferred in colonies of the other species $(r=0.42 \pm 0.10)$.

\section{Relatedness and effective mating frequency variation within species}

Comparing the effective mating frequency and intra-colonial relatedness between polygynous and monogynous colonies yielded contrasting results in A. heyeri and A. lobicornis. In A. heyeri, the average effective mating frequency of queens in polygynous colonies (average $\overline{m_{e}} \pm$ std. error $=3.17 \pm 0.41$ ) was significantly lower in comparison to the effective mating frequency of queens in monogynous colonies $\left(m_{e}=4.92 \pm 0.51\right.$; Welch $t$-test: $t_{14.35}=2.65$, $p=0.0187$; Fig. 5a). On the other hand, we detected no significant difference between the intra-colonial relatedness of monogynous $(r \pm$ std. error $=0.38 \pm 0.02)$ and polygynous ( $r=0.26 \pm 0.07)$ colonies of $A$. heyeri ( $t$-test: $t_{23}=2.00$, $p=0.057$; Fig. 6a).
Table 1 Summary of social structure in colonies of five Acromyrmex leaf-cutting ants. The numbers in parentheses in the top row represent the number of polygynous colonies over the total sampling for the corresponding species

\begin{tabular}{llllll}
\hline & A. ambiguus & A. crassispinus & A. heyeri & A. lobicornis & A. lundii \\
\hline Number of colonies sampled & 4 & 18 & 25 & 18 & 28 \\
Frequency of polygyny & $25.00 \%$ & $11.00 \%$ & $16.00 \%$ & $22.22 \%$ & $0.0 \%$ \\
& $(1 / 4)$ & $(2 / 18)$ & $(4 / 25)$ & $(4 / 18)$ & $(0 / 28)$ \\
Maximum number of queens & 2 & 3 & 2 & 4 & 1 \\
Minimum number of mates & 4 & 1 & 2 & 1 & 1 \\
Maximum number of mates & 10 & 12 & 12 & 4 & 6 \\
Average number of queens per colony & 1.25 & 1.17 & 1.15 & 1.39 & 1 \\
(std. deviation) & $(0.50)$ & $(0.51)$ & $(0.37)$ & $(0.78)$ & $(\mathrm{N} / \mathrm{A})$ \\
Observed mating frequency M & 6.000 & 6.476 & 5.500 & 2.875 & 4.179 \\
(std. deviation) & $(2.345)$ & $(3.737)$ & $(2.570)$ & $(1.076)$ & $(1.634)$ \\
Effective mating frequency m & 5.919 & 4.510 & 4.433 & 2.356 & 3.329 \\
(std. deviation) & $(2.405)$ & $(2.849)$ & $(2.197)$ & $(0.796)$ & $(1.395)$ \\
Reproductive skew S & 0.091 & 0.414 & 0.257 & 0.258 & 0.256 \\
(std. deviation) & $(0.135)$ & $(0.231)$ & $(0.150)$ & $(0.206)$ & $(0.213)$ \\
$\begin{array}{l}\text { Intra-colony relatedness } \mathrm{r} \\
\text { (std. error) }\end{array}$ & 0.423 & 0.459 & 0.355 & 0.461 & 0.464 \\
\hline & $(0.096)$ & $(0.036)$ & $(0.024)$ & $(0.036)$ & $(0.025)$ \\
\hline
\end{tabular}


Fig. 2 Mating frequency in four species of Acromyrmex leaf-cutting ants. (A) Observed mating frequency, the total number of males mated to a single queen. (B) Effective mating frequency, the effective number of males contributing equally to a queen's offspring production. Letters above the boxes represent the significance groups recovered from pairwise Mann-Whitney $U$ test with FDR correction $(\alpha=0.05)$. Red (gray) boxes represent polygynous species; blue (black) boxes represent monogynous species. (Parenthesis colors refer to grayscale equivalences)
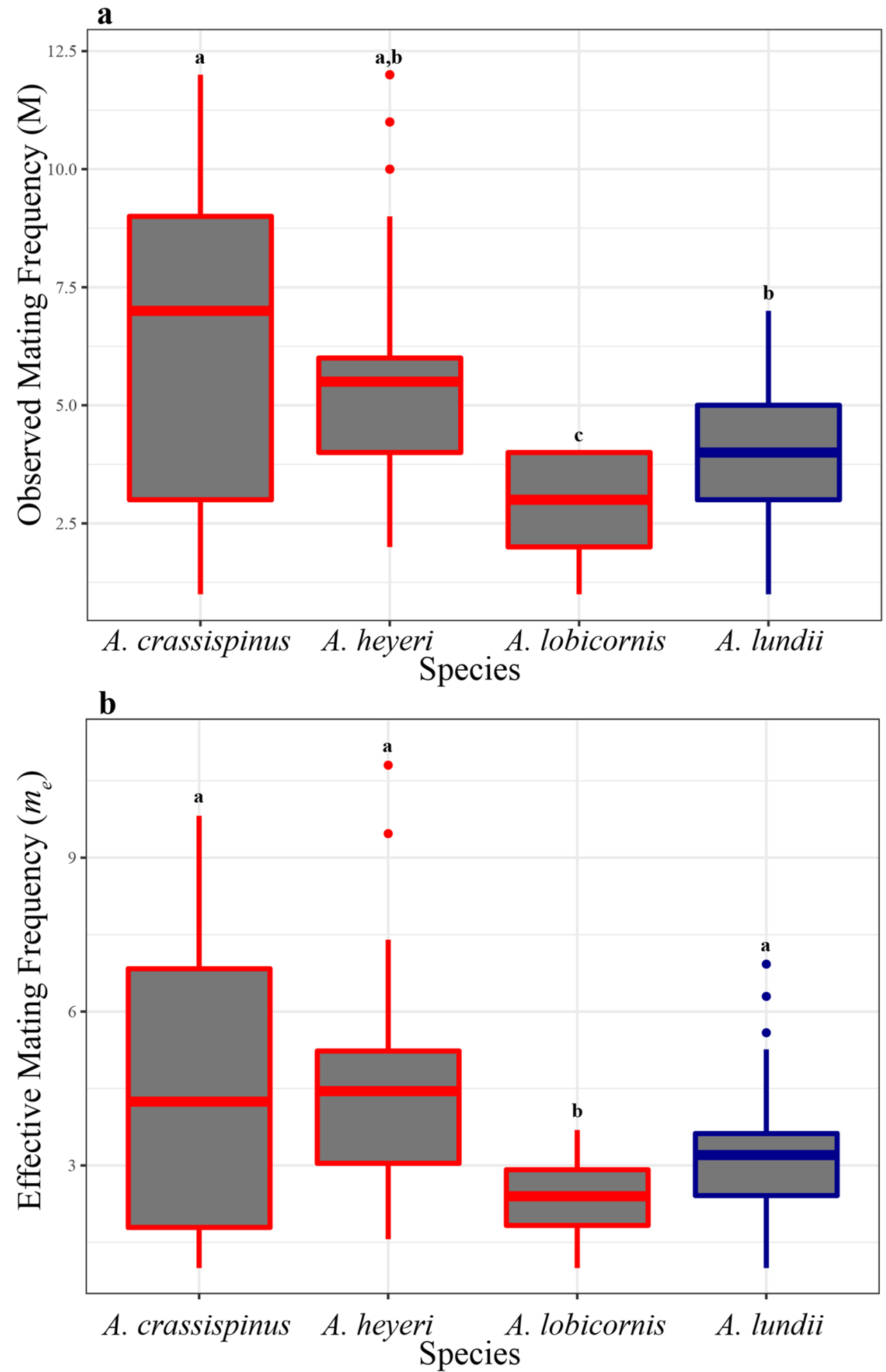

Conversely, in A. lobicornis there was no significant difference in the effective mating frequency of polygynous colonies $\left(m_{e}=2.24 \pm 0.39\right)$ compared to that of monogynous colonies $\left(m_{e}=2.53 \pm 0.21, t\right.$-test: $\mathrm{t}_{16}=0.65$, $p=0.525$; Fig. $5 b$ ). However, we found that average relatedness was significantly lower in polygynous colonies of A. lobicornis $\left(r=0.33 \pm 5.90 \times 10^{-2}\right)$ compared to monogynous colonies $\left(r=0.51 \pm 3.66\right.$; $t$-test: $t_{16}=2.67$, $p=0.0167$; Fig. 6b). These results suggest relatedness may be affected in different ways by variation in mating frequency and queen number in different species of leaf-cutting ants, likely depending on the relatedness of 


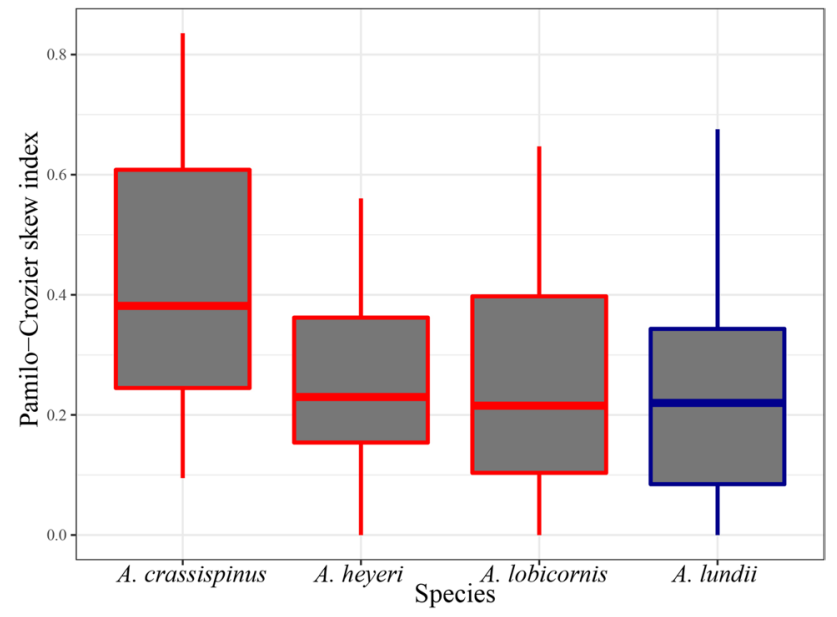

Fig. 3 Pamilo-Crozier skew index in workers of four species of Acromyrmex leaf-cutting ants. Red (gray) boxes represent polygynous species; blue (black) boxes represent monogynous species. (Parenthesis colors refer to grayscale equivalences)

reproductively active queens and their mates. Interestingly, relatedness appears to be affected primarily by either mating frequency or queen number in different species, as opposed to a combination of both.

\section{Discussion}

We characterized the social structure and mating biology of five species of South American Acromyrmex leaf-cutting ants. Our analysis infers one species, A. lundii, as monogynous, while the other four species, A. ambiguus, $A$. crassispinus, A. heyeri, and A. lobicornis are facultatively polygynous. All five species are polyandrous. Our findings suggest that variation in relatedness is affected differently by variation in mating biology in different species, and that species have no appreciable differences in reproductive skew among males mated to the same queens. Finally, we find that variation in mating biology and social structure have little effect on the intra-colonial relatedness.

\section{Patterns of association between mating biology and social structure in ants}

Our results reveal that mating biology is variable among South American species of Acromyrmex leaf-cutting ants and that mating behavior and social structure occur in different combinations across leaf-cutting ants. Polygyny and a relatively high mating frequency $\left(\mathrm{m}_{e} \geq 3.50\right)$ were repeatedly observed, with variation in both traits occurring independently of one another between species. One of the studied species, A. lundii, appears to have reverted to obligate monogyny, while another, A. lobicornis, showed a significantly lower effective mating frequency compared
Fig. 4 Scatterplot of average intra-colonial relatedness vs. effective mating frequency (natural $\log$ ) in four species of Acromyrmex leaf-cutting ants. Warm (gray) colors represent facultatively polygynous species; the blue (black) line and circles represent monogynous species. A. lobicornis (a polygynous species, diamonds) is represented with a dashed line for convenience in grayscale. (Parenthesis colors refer to grayscale equivalences)

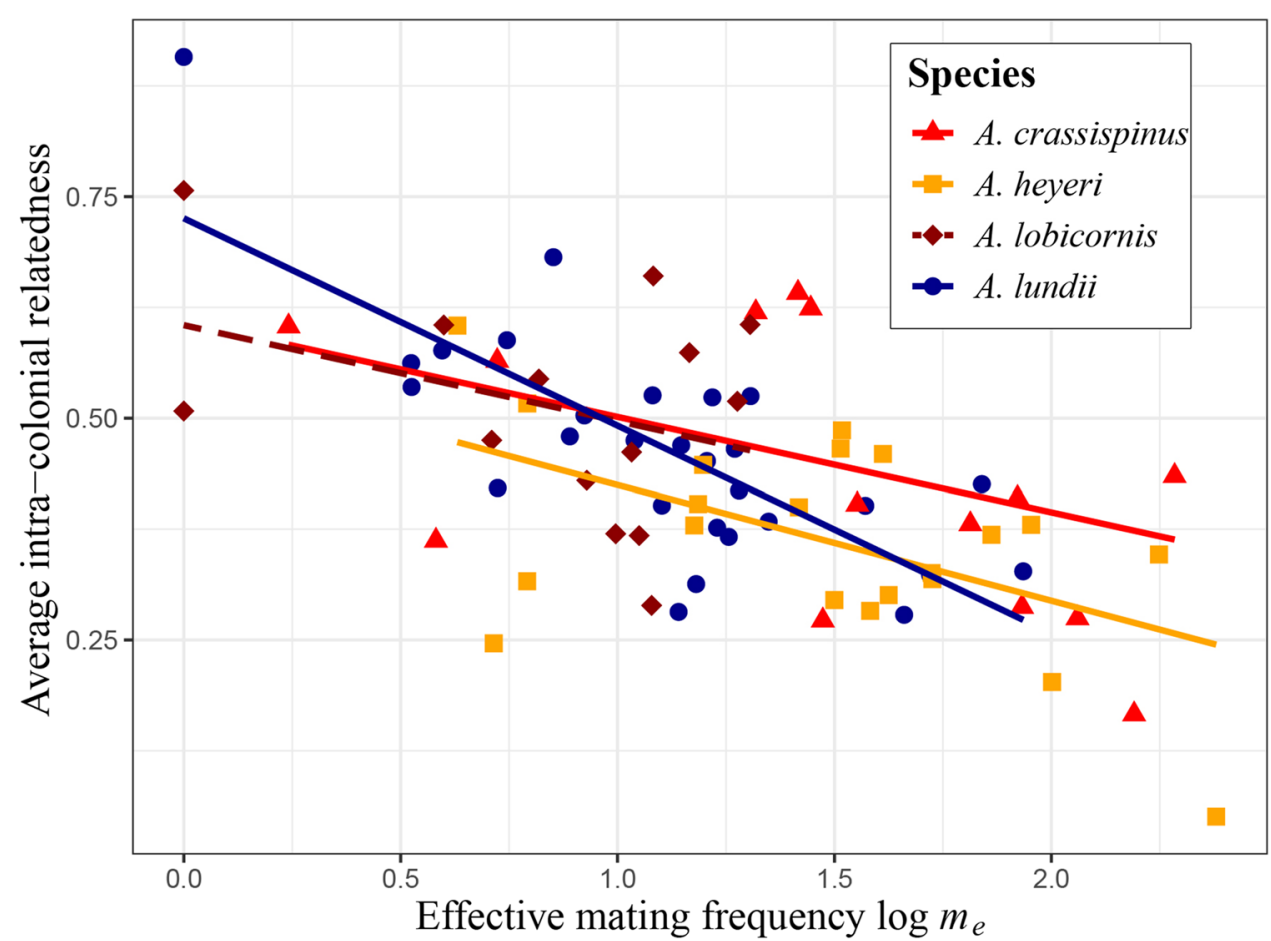


Fig. 5 Effective mating frequency in monogynous and polygynous colonies of (a) Acromyrmex heyeri and (b) A. lobicornis. Red (gray) boxes represent facultatively polygynous colonies; blue (black) boxes represent monogynous colonies. (Parenthesis colors refer to grayscale equivalences)
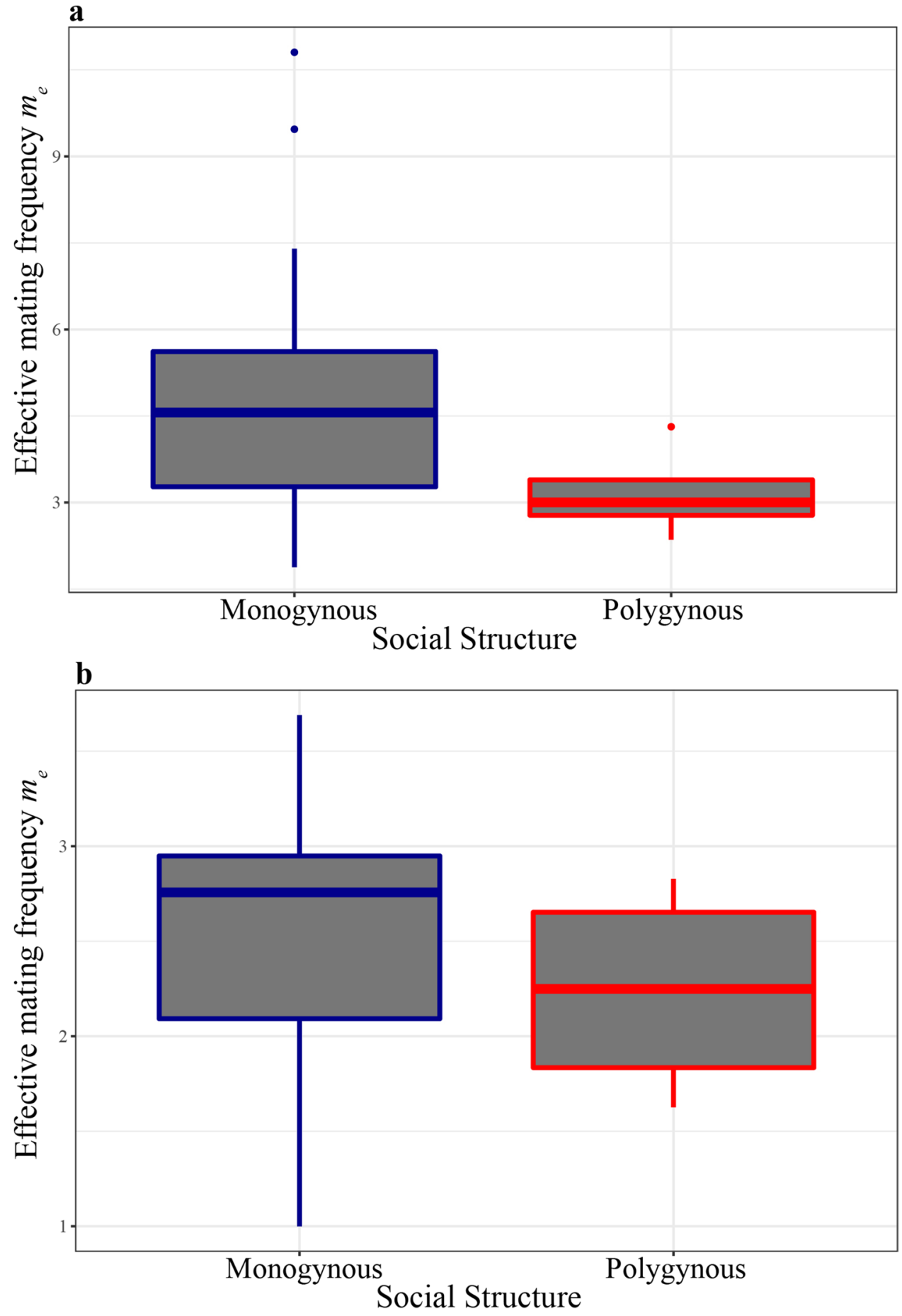

to the others. It is theoretically possible that the inferred monogyny of $A$. lundii could stem from the non-sampling of polygynous colonies. However, the frequency of polygynous colonies in the other sampled species ranged from 11 to $28 \%$, and the number of sampled colonies was larger for $A$. lundii than for any other species in our study. Calculating the probability of not sampling a polygynous colony out of 28 total colonies based on a binomial distribution, and assuming a conservative rate of polygyny of $10 \%$, the binomial probability of sampling no polygynous colonies is 0.05 , suggesting that our results are unlikely to stem from sampling error. Interestingly, these inter-specific variations in mating biology appear to have little impact on average intra-colonial relatedness in species (Fig. 4). The only noteworthy variation seems to be seen in colonies of $A$. heyeri, which have slightly lower relatedness on average (Fig. 4). Variation in intra-colonial relatedness across species is not influenced by species-level social structure (i.e., whether a species 
Fig. 6 Average intra-colonial relatedness in monogynous and polygynous colonies of Acromyrmex heyeri (a) and A. lobicornis (b). Red (gray) boxes represent polygynous colonies; blue (black) boxes represent monogynous colonies. (Parenthesis colors refer to grayscale equivalences)
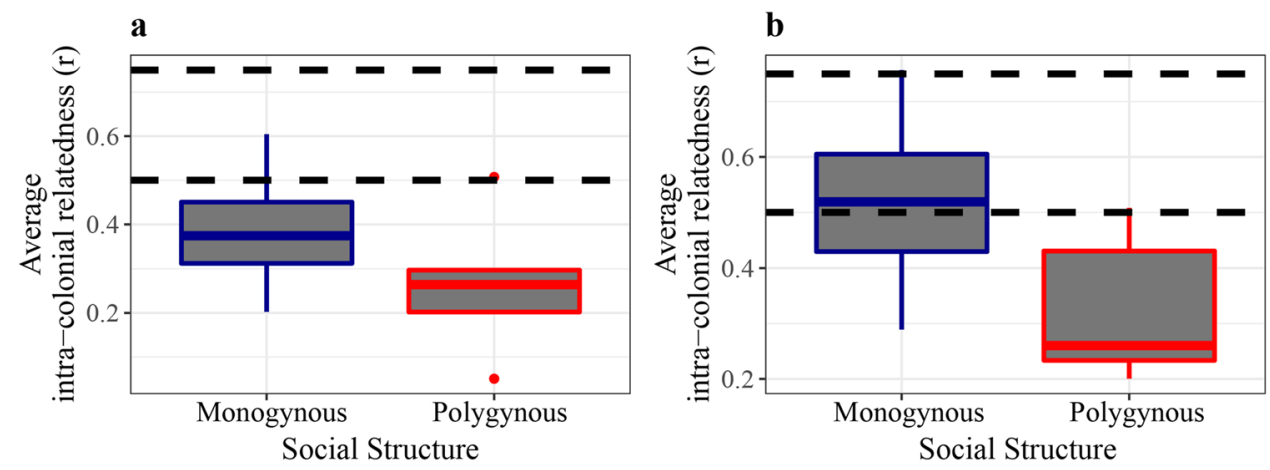

was facultatively polygynous or obligately monogynous), but was significantly affected by effective mating frequency (Fig. 4, Table 1). This result was unsurprising given the limited number of monogynous colonies in the sample, and the fact that polygynous colonies were excluded from the regression analysis, thus showing only the predictable negative effect of mating frequency on relatedness. On the other hand, the effect of effective mating frequency on intra-colonial relatedness was itself dependent on the species social structure, with a larger effect in the strictly monogynous $A$. lundii compared to the other, socially polymorphic species (Fig. 4). This result suggests that relatedness responds differently to variations in mating biology between monogynous and polygynous species, even in monogynous colonies of species that are facultatively polygynous. The overall general pattern of trait association between social structure, mating biology, and relatedness appears to be unrelated to the phylogenetic relationship between the investigated species (Fig. 7).

Previous studies investigated the mating biology of four Central and South American Acromyrmex leaf-cutting ant species. Diehl and colleagues (Diehl et al. 2001) conducted a qualitative investigation of mating biology and colony structure in the South American species A. heyeri and Amoimyrmex striatus, finding facultative polygyny and prevalent polyandry in both species, which is consistent with our results. Boomsma and colleagues (Boomsma et al. 1999) investigated the mating biology of the monogynous Central American species A. octospinosus, while Bekkevold and colleagues (Bekkevold et al. 1999) as well as Nehring and colleagues (Nehring et al. 2018) investigated both mating biology and social structure in its close relative A. echinatior. The monogynous $A$. octospinosus was found to have a high effective queen mating frequency $\left(m_{e}=3.93 ; n=22\right)$, and a mean pedigree relatedness (calculated from effective mating frequency rather than from genotypic data) of 0.38 . Acromyrmex echinatior was found to be facultatively polygynous (Bekkevold et al. 1999; Nehring et al. 2018) and reproductive queens were found to have a relatively lower effective mating frequency $\left(m_{e}=2.33 ; n=20\right)$, although the estimate was based on monogynous colonies only $(n=13)$ (Bekkevold et al. 1999). Average intra-colonial relatedness in these A. echinatior colonies was estimated from the effective mating frequency to be 0.41 . Based on these results, A. echinatior appears similar to A. lobicornis with a low effective mating frequency, facultative polygyny, and high intra-colonial relatedness, while A. octospinosus presents a unique pattern of trait association with high effective mating frequency, monogyny, and low intra-colonial relatedness.

Overall, among the six Acromyrmex species with detailed sampling for mating biology and social structure, we cannot identify any consistent pattern of trait association between social structure and mating biology. In fact, only A. echinatior and A. lobicornis appear to have converged on a common association phenotype (with polygyny, low effective mating frequency, and relatively high mean intracolonial relatedness). All other species were found to display unique patterns of trait associations (Table 2). Evolutionary changes in social structure and mating frequency also appear to be phylogenetically unrelated (Fig. 7). Interestingly, polygyny and polyandry are not consistently negatively correlated in these Acromyrmex leaf-cutting ants.

In all instances, the mating behavior of leaf-cutting ants was characterized as snapshots in time, rather than characterizing the actual lifetime reproductive behavior of a colony and the queen(s) within it. Lifetime variation in sperm usage and colony structure (resulting, for example, from the adoption of new queens) could lead to significant variation in intracolonial relatedness, effective mating frequency, or queen number during a colony's lifespan, of which we can only document a limited view. A full investigation of parentage and relatedness through a colony's lifetime would be fascinating but problematic in leaf-cutting ants given the long lifespan of queens. However, some evidence suggests that the composition of sperm used by queens does not change over long periods of time, suggesting that such snapshots may indeed provide an accurate view of paternity in a colony (Stürup et al. 2014). Furthermore, this limitation in time may also explain the importance of species-level social structure (i.e., whether a species is characterized a polygynous vs. monogynous), as lifetime variation in queen number in colonies can have a significant impact on the relatedness and population structure of these species. In our sampling, the 


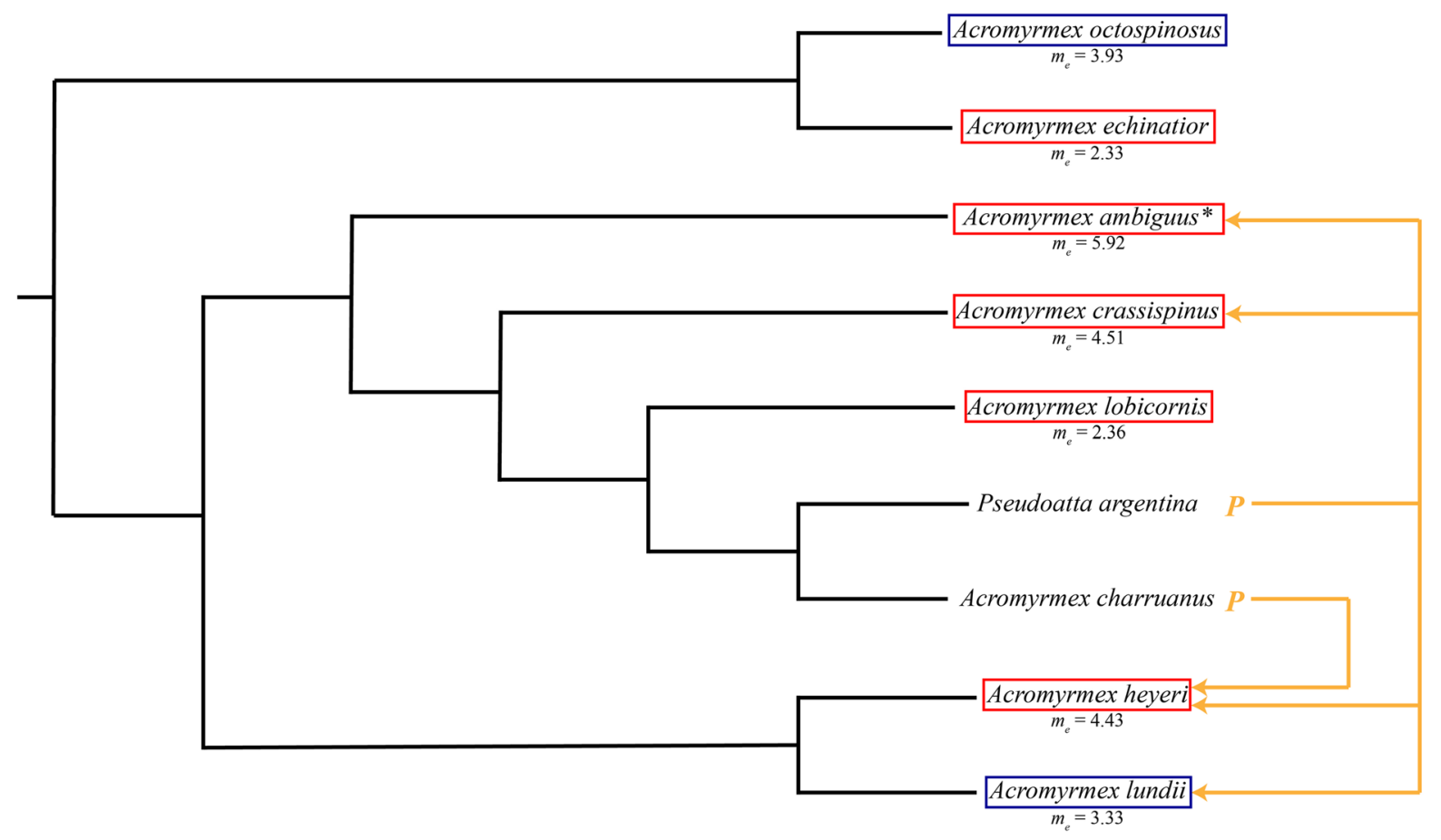

Fig. 7 Phylogenetic distribution of mating biology and social structure in Acromyrmex leaf-cutting ants. Species boxed in red (gray) are socially polymorphic (i.e., facultatively polygynous); species boxed in blue (black) are obligately monogynous. A yellow (gray) P denotes inquiline social parasites, and arrows show host-parasite relationships. Data for A. ambiguus, denoted by an asterisk, is based on low

species-level classification was shown to significantly affect the relationship between mating frequency and relatedness, implying that a higher effective mating frequency in obligately monogynous species had a larger impact on colony relatedness compared to species with facultative polygyny (Fig. 4).

Functional polygyny in ants may be either primary, resulting from multiple queens co-founding colonies (pleometrosis), or secondary, resulting from the adoption of new queens in established mature colonies. While many examples of pleometrotic species are known, only a few

Table 2 Summary of patterns of trait association between mating biology and social structure among six species of Acromyrmex leaf-cutting ants. High effective mating frequency was defined as a sample size. The Acromyrmex phylogeny is modified from Rabeling et al. 2018. Information about the social structure and mating frequency of the Central American leaf-cutting ant species A. echinatior and A. octospinosus were generated by Boomsma et al. 1999 and Bekkevold et al. 1999. (Parenthesis colors refer to grayscale equivalences)

have been documented to actually result in functional primary polygyny (Bourke \& Franks, 1995; Johnson, 2004; Mintzer, 1987; Rissing et al. 1986; Trunzer et al., 1998). In contrast, secondary polygyny appears to be more common in ants (Boomsma et al., 2014; Bourke \& Franks, 1995; Hölldobler \& Wilson, 1977). The mode of polygyny in the Acromyrmex species sampled here is unknown. Pleometrosis has been observed in A. crassispinus, but in all cases but one queen died before colony maturation (DiehlFleig \& de Araújo, 1996). In contrast, primary polygyny has been well characterized in the North American desert

value of $m_{e}=3.50$ or above. High mean intracolonial relatedness was defined as a value of $r=0.40$ or above. Thresholds were selected as the approximate averages of variables

\begin{tabular}{lllll}
\hline & $\mathrm{m}_{\mathrm{e}}$ & Social structure & Mean intracolonial relatedness & Source \\
\hline A. crassispinus & High & Polygyny & High & This study \\
A. echinatior & Low & Polygyny & High & Bekkevold et al. 1999 \\
A. heyeri & High & Polygyny & Low & This study \\
A. lobicornis & Low & Polygyny & High & This study \\
A. lundii & Low & Monogyny & High & This study \\
A. octospinosus & High & Monogyny & Low & Boomsma et al. 1999 \\
\hline
\end{tabular}


species A. versicolor (Rissing et al., 1986; Rissing et al., 1989), and has been observed under laboratory conditions in the South American species Amoimyrmex striatus (Diehl-Fleig \& de Araújo, 1996). On the other hand, queen adoption has been observed in the laboratory in a single species, the South American A. subterraneus molestans (Souza et al. 2005). Whether the observed polygyny in our sampled species is primary or secondary is unknown. Circumstantial evidence in A. crassispinus would indicate that the observed polygyny may be secondary (Diehl-Fleig \& de Araújo, 1996).

\section{Independent evolution of polygyny and polyandry}

When comparing Acromyrmex species to other fungusgrowing ant species, and to other species across the ant tree of life, the co-occurrence of polygyny and polyandry in the same species is relatively rare, or at least a rarely documented phenomenon. If polygyny and polyandry evolve chiefly to increase the genetic variability within a colony, the prediction follows that polygyny and polyandry should be negatively correlated in eusocial insects; that is, polygynous species should be primarily monandrous, and monogynous lineages polyandrous (Keller and Reeve 1994). This association has been identified across ants (Schmid-Hempel and Crozier 1999; Hughes et al. 2008b). In fungus-growing ants, this pattern is weak, and for Acromyrmex leaf-cutting ants, we do not observe this negative association. Outside of Acromyrmex only few fungus-growing ant species in the genera Mycocepurus and Sericomyrmex are known to display facultative polygyny (Villesen et al. 2002; Rabeling et al. 2007a, b, 2014b). The evolutionary transition from monandry to multiple mating has been well documented as a single evolutionary transition at the origin of the socalled higher attines (Villesen et al. 1999, 2002; Nygaard et al. 2016), comprising the leaf-cutting ants, Acromyrmex, Amoimyrmex, and Atta, as well as the genera Mycetomoellerius, Paratrachymyrmex, Sericomyrmex, Trachymyrmex, and Xerolitor (Sosa-Calvo et al. 2018; Solomon et al. 2019). Thus, it appears that facultative polygyny evolves independently of polyandry in fungus-growing ants. Notably, functional secondary polygyny is absent in the closely related leaf-cutting ant genus Atta, despite the fact that Atta species are known to be polyandrous (Fjerdingstad et al. 1998; Fjerdingstad and Boomsma 2000; Helmkampf et al. 2008; Evison and Hughes 2011). When both traits co-occur in a clade, selection may act on both independently, modulating each trait individually to reach an optimum based on the individualized ecological and social niche occupied by a species (e.g., pathogen resistance, worker caste polymorphism, etc. See "Introduction"). Alternatively, these traits may not be under strong enough selection to overcome drift, and trait associations could be the result of random variation in these traits in these species. However, based on the strong evolutionary implications of both polygyny and multiple mating, it seems unlikely that drift only would drive the evolution of these traits. Our results show remarkable consistency in average intra-colonial relatedness in Central and South American species of Acromyrmex (Table 2, Figs. 4 and 7 ). We found that relatedness varies significantly with effective mating frequency and social structure, both within and between species (Fig. 4), and we found significant variation in effective mating frequency and queen number both between and within species (Fig. 2). In combination, these results suggest that species may converge toward an optimum intra-colonial relatedness. This convergence appears to be mediated via complex and dynamic combinations of multiple mating and multi-queen breeding. Interestingly, the patterns of association appear not to be limited to a straightforward prediction of negative association between mating frequency and queen number, possibly implying that other unidentified ecological factors may play a role in the mediation of intra-colonial relatedness. An alternative explanation may be that relatedness is not under selection in these colonies, and the observed similarities are simply the result of chance convergence due to the trait associations in different species and other, unaccounted factors.

Outside of the fungus-growing ants, studies investigating the mating biology of Formica, Myrmecia, and Myrmica species, in which polyandry and polygyny co-occur, have produced different and often contradicting results (Pamilo 1993; Pedersen and Boomsma 1999a; Hannonen et al. 2004; Qian et al. 2011). These findings further support the hypothesis that, while polyandry and polygyny are negatively correlated in general, when both traits co-occur in groups of closely related species, they can evolve independently at shallow evolutionary timescales, dynamically filling speciesspecific ecological and social niches.

\section{Ecological factors promoting polygyny and polyandry}

Two major hypotheses have been proposed to explain the evolution of polyandry in eusocial insects. The sperm limitation hypothesis suggests that multiple males are needed to provide enough sperm to the queen of large colonies. The hypothesis has been widely tested in the literature, and has received support in honeybees (Kraus et al. 2004), as well as in the leaf-cutting ant Atta colombica (Fjerdingstad and Boomsma 1998) and army ants (Kronauer and Boomsma 2007). In this case, polyandry is expected to evolve more readily in association with the evolution of large colony sizes. In Acromyrmex, investigated species form large colonies (Burchill and Moreau 2016 and references therein). Interestingly, in the fungus-growing ants, the transition to large colony size is observed in the ancestor of the 
leaf-cutting ants, after the inferred origin of polyandry in "higher" attines (Villesen et al. 2002; Burchill and Moreau 2016). Most notably, the hypothesis predicts that polyandrous species with larger colonies should exhibit significant reproductive skew among patrilines following natural variation in sperm contribution from males, because the queen has to use the entirety of the sperm stored in her spermatheca (Kraus and Moritz 2010; Barth et al. 2014). This pattern was observed in the Panamanian species A. echinatior (Stürup et al. 2014), and was inferred for South American Acromyr$m e x$ species in this study. Paternal skew was observed for all multiply mated queens, thus providing circumstantial support for this prediction of the sperm limitation hypothesis.

The workers of leaf-cutting ants are highly polymorphic with large workers accomplishing foraging and exploration tasks outside the nest, while small workers remain inside the nest tending to the brood and the fungus garden. In $A$. echinatior, worker morph determination is complex and has been inferred to be in part genetically determined (Hughes et al. 2003; Hughes and Boomsma 2007). In this system, high mating frequency by the queen was interpreted to be favorable because it increases the genetic diversity of workers and allows for a better optimization of colony efficiency through the ratio of large vs. small workers (Hughes and Boomsma 2007). More generally in leaf-cutting ants, worker task specialization is associated with variability in size, contrasting with the rest of the fungus-growing ants, in which task specialization typically depends on age-dependent factors (Murakami et al. 2000). This could represent a shift in the determination of division of labor in colonies, in which genetic factors affecting worker size determination are linked with factors determining worker task specialization. Our data does not allow us to directly address any potential genetic factors in the size determination of workers in Acromyrmex colonies. Future studies may benefit from investigating any paternal differences in the size distribution of workers.

To conclude, our results are consistent with the hypothesis that relatedness may be the ultimate subject of selection, resulting from the trade-off between kin selection and the ecological benefits of genetic diversity outlined above. Multiple mating and polygyny appear to evolve along independent trajectories, and their respective effect on relatedness is dynamic and inconsistent between strictly monogynous and socially polymorphic species, as well as between socially polymorphic species themselves.

\section{Evolutionary consequences of mating biology and social structure}

The dynamic evolution of relatedness, mating behavior, and social structure is expected to promote the evolution of alternative life history strategies, such as the emergence of reproductive cheating and social parasitism. A reduction in relatedness has been documented to promote the emergence of cheating lineages in many social taxa (Kuzdzal-Fick et al. 2011). Furthermore, social structure in ants plays an important role in the emergence and maintenance of inquiline social parasitism, in which a parasite queen takes advantage of the host's workers to reproduce. Polygyny itself is thought to be a pre-condition for the evolution of social parasitism in many species (Bourke and Franks 1991; Nonacs and Tobin 1992; Dahan and Rabeling, in review). Once evolved, social parasitism can become an important source of evolutionary pressure on host species, as co-evolutionary dynamics would be expected between host and parasites. Factors promoting nestmate recognition and policing in hosts would thus experience rapid evolution, influencing relatedness, mating behavior, and social structure (Brandt et al. 2005).

Our study shows that the known host species of two inquiline social parasites, $A$. charruanus and $P$. argentina, are facultatively polygynous, which is consistent with the hypothesis that polygyny is important for the origin and maintenance of inquilinism in ants (Fig. 7) (Bourke and Franks 1991; Dahan and Rabeling, in review). Interestingly, A. lundii was inferred to be monogynous and future studies will be needed to resolve the evolutionary history of social parasitism relative to the host's reversal from poly- to monogyny. In general, our results add to the growing body of evidence that the complex social structures of Acromyrmex leaf-cutting ants provide a fertile breeding ground for the parallel evolution of social parasitism.

\section{Conclusions}

In summary, we found a complex and dynamic association between colony structure and mating biology in leaf-cutting ants of the genus Acromyrmex. Our findings suggest that Acromyrmex leaf-cutting ants are socially polymorphic, and the association between polygyny and polyandry seems to be governed by species-specific fitness optima that may be related to ecological conditions.

Supplementary Information The online version contains supplementary material available at https://doi.org/10.1007/s00265-021-03113-1.

Acknowledgements We gratefully acknowledge the Dirección General de Recursos Naturales Renovables for permission to conduct fieldwork in Uruguay and the Conselho Nacional de Desenvolvimento Científico e Tecnológico ( $\mathrm{CNPq})$, the Instituto Brasileiro do Meio Ambiente e dos Recursos Naturais Renováveis (IBAMA), and the ICMBio for permission to conduct fieldwork in Brazil. Allie Born assisted in the molecular laboratory. Brian Haney and Ti Eriksson kindly assisted in establishing the microsatellite analysis pipeline at ASU. Marek Borowiec and Kyle Gray provided helpful comments on an earlier version of this manuscript. 
Author contribution $\mathrm{CR}$ designed the study; $\mathrm{CR}$ and MB planned and conducted field work; CR developed molecular markers; RAD, NKG, and BG conducted laboratory work; RAD and NKG analyzed molecular data; RAD conducted statistical analyses; RAD and CR wrote the manuscript. All authors commented on and approved the manuscript.

Funding This research was financially supported by Arizona State University and the University of Rochester, an ASU Research \& Training Initiative Grant, and the US National Science Foundation (NSF DEB1654829 \& NSF CAREER DEB-1943626).

Data availability All genotype data and sampling information are deposited on Dryad data repository and are available at https://datad ryad.org/stash/share/FN8RkYyO6MPwcNzYOcwUtkRIVTPHDK OQhTU3Uepy_5o

Code availability Not applicable.

\section{Declarations}

Conflict of interest The authors declare no competing interests.

Ethics approval Not applicable.

Consent to participate Not applicable.

Consent for publication Not applicable.

Open Access This article is licensed under a Creative Commons Attribution 4.0 International License, which permits use, sharing, adaptation, distribution and reproduction in any medium or format, as long as you give appropriate credit to the original author(s) and the source, provide a link to the Creative Commons licence, and indicate if changes were made. The images or other third party material in this article are included in the article's Creative Commons licence, unless indicated otherwise in a credit line to the material. If material is not included in the article's Creative Commons licence and your intended use is not permitted by statutory regulation or exceeds the permitted use, you will need to obtain permission directly from the copyright holder. To view a copy of this licence, visit http://creativecommons.org/licenses/by/4.0/.

\section{References}

Baer B, Schmid-Hempel P (1999) Experimental variation in polyandry affects parasite loads and fitness in a bumble-bee. Nature 397:151-154. https://doi.org/10.1038/16451

Banschbach VS, Herbers JM (1996) Complex colony structure in social insects: I. Ecological Determinants and Genetic Consequences Evolution 50:285-297. https://doi.org/10.2307/2410800

Barth MB, Moritz RFA, Kraus FB (2014) The evolution of extreme polyandry in social insects: insights from army ants. PLoS ONE 9:e105621. https://doi.org/10.1371/journal.pone.0105621

Bekkevold D, Frydenberg J, Boomsma JJ (1999) Multiple mating and facultative polygyny in the Panamanian leafcutter ant Acromyrmex echinatior. Behav Ecol Sociobiol 46:103-109. https://doi. org/10.1007/s002650050598

Bhargava A, Fuentes FF (2010) Mutational dynamics of microsatellites. Mol Biotechnol 44:250-266. https://doi.org/10.1007/ s12033-009-9230-4
Boomsma JJ (2009) Lifetime monogamy and the evolution of eusociality. Philos Trans R Soc Lond B Biol Sci 364:3191-3207. https:// doi.org/10.1098/rstb.2009.0101

Boomsma JJ, Fjerdingstad EJ, Frydenberg J (1999) Multiple paternity, relatedness and genetic diversity in Acromyrmex leaf-cutter ants. Proc R Soc B Biol Sci 266:249. https://doi.org/10.1098/rspb. 1999.0629

Boomsma JJ, Huszár DB, Pedersen JS (2014) The evolution of multiqueen breeding in eusocial lineages with permanent physically differentiated castes. Anim Behav 92:241-252. https://doi.org/ 10.1016/j.anbehav.2014.03.005

Boomsma JJ, Kronauer DJC, Pedersen JS (2009) The evolution of social insect mating systems. In: Gadau J, Fewell JH (eds) Organization of insect societies: from genome to sociocomplexity. Harvard University Press, Cambridge, MA, pp 3-25

Boomsma JJ, Ratnieks FLW (1996) Paternity in Eusocial Hymenoptera. Philos Trans R Soc B Biol Sci 351:947-975. https://doi.org/ 10.1098/rstb.1996.0087

Bourke AFG (2014) Hamilton's rule and the causes of social evolution. Philos Trans R Soc B Biol Sci 369:20130362. https://doi.org/10. 1098/rstb.2013.0362

Bourke AFG, Franks NR (1995) Social evolution in ants. Princeton University Press, Princeton, NJ

Bourke AFG, Franks NR (1991) Alternative adaptations, sympatric speciation and the evolution of parasitic, inquiline ants. Biol J Linn Soc 43:157-178. https://doi.org/10.1111/j.1095-8312.1991. tb00591.x

Brandt M, Foitzik S, Fischer-Blass B, Heinze J (2005) The coevolutionary dynamics of obligate ant social parasite systems-between prudence and antagonism. Biol Rev Camb Philos Soc 80:251267. https://doi.org/10.1017/S1464793104006669

Breed MD, Welch CK, Cruz R (1994) Kin discrimination within honey bee (Apis mellifera) colonies: an analysis of the evidence. Behav Processes 33:25-39. https://doi.org/10.1016/0376-6357(94) 90058-2

Burchill AT, Moreau CS (2016) Colony size evolution in ants: macroevolutionary trends. Insectes Soc 63:291-298. https://doi.org/ 10.1007/s00040-016-0465-3

Buschinger A (2009) Social parasitism among ants: a review (Hymenoptera: Formicidae). Myrmecological News 12:219-235

Cahan S, Julian GE (1999) Fitness consequences of cooperative colony founding in the desert leaf-cutter ant Acromyrmex versicolor. Behav Ecol 10:585-591. https://doi.org/10.1093/beheco/10.5. 585

Choe JC, Crespi BJ (1997) Social behavior in insects and arachnids Cambrige University Press, Cambridge

Clutton-Brock TH (1985) Size, sexual dimorphism, and polygyny in primates. In: Jungers WL (ed) Size and scaling in primate biology. Springer Sciences + Business Media, LLC, New York, pp $51-59$

Cornwallis CK, West SA, Davis KE, Griffin AS (2010) Promiscuity and the evolutionary transition to complex societies. Nature 466:969-972. https://doi.org/10.1038/nature09335

Crozier RH, Fjerdingstad EJ (2001) Polyandry in social Hymenopteradisunity in diversity? Ann Zool Fennici 38:267-285

Delabie JHC (1989) Observações sobre a ocorrencia de poliginia em colonias de Acromyrmex subterraneus brunneus Forel 1893, em Cacauais. (Formicidae, Myrmicinae, Attini). An Da Soc Entomológica Do Bras 18:193-197

Diehl-Fleig E, de Araújo AM (1996) Haplometrosis and pleometrosis in the ant Acromyrmex striatus (Hymenoptera: Formicidae). Insectes Soc 43:47-51. https://doi.org/10.1007/BF01253955

Diehl E, de Araújo AM, Cavalli-Molina S (2001) Genetic variability and social structure of Colonies in Acromyrmex heyeri and $A$. striatus (Hymenoptera: Formicidae). Brazilian J Biol 61:667678. https://doi.org/10.1590/S1519-69842001000400017 
Evison SEF, Hughes WOH (2011) Genetic caste polymorphism and the evolution of polyandry in Atta leaf-cutting ants. Naturwissenschaften 98:643-649. https://doi.org/10.1007/ s00114-011-0810-3

Fjerdingstad EJ, Boomsma JJ (1998) Multiple mating increases the sperm stores of Atta colombica leafcutter ant queens. Behav Ecol Sociobiol 42:257-261. https://doi.org/10.1007/s002650050437

Fjerdingstad EJ, Boomsma JJ (2000) Queen mating frequency and relatedness in young Atta sexdens colonies. Insectes Soc 47:354356. https://doi.org/10.1007/PL00001730

Fjerdingstad EJ, Boomsma JJ, Thorén P (1998) Multiple paternity in the leafcutter ant Atta colombica - a microsatellite DNA study. Heredity 80:118-126. https://doi.org/10.1038/sj.hdy.6882470

Fowler HG (1985) Leaf-cutting ants of the genera Atta and Acromyrmex of Paraguay (Hymenoptera Formicidae). Dtsch Entomol Zeitschrift 32:19-34. https://doi.org/10.1002/mmnd.19850 320105

Fowler HG (1988) Taxa of the neotropical grass-cutting ants, Acromyrmex (Moellerius)(Hymenoptera: Formicidae: Attini). Científica 16:281-295. https://doi.org/10.5281/zenodo.26293

Gallardo A (1916) Notes systématique et éthologiques sur les fourmis attines de la République Argentine. An Del Mus Nac Hist Nat Buenos Aires 28:317-344

Gonçalves CR (1961) O genero Acromyrmex no Brasil (Hym. Formicidae). Stud Entomol 4:113-180

Haney BR, Fewell JH (2018) Ecological drivers and reproductive consequences of non-kin cooperation by ant queens. Oecologia 187:643-655. https://doi.org/10.1007/s00442-018-4148-9

Hannonen M, Helanterä H, Sundström L (2004) Habitat age, breeding system and kinship in the ant Formica fusca. Mol Ecol 13:15791588. https://doi.org/10.1111/j.1365-294X.2004.02136.x

Hannonen M, Sundström L (2003) Worker nepotism among polygynous ants. Nature 421:910. https://doi.org/10.1038/421910a

Hartke TR, Baer B (2011) The mating biology of termites: a comparative review. Anim Behav 82:927-936. https://doi.org/10.1016/j. anbehav.2011.07.022

Helmkampf M, Gadau J, Feldhaar H (2008) Population- and sociogenetic structure of the leaf-cutter ant Atta colombica (Formicidae, Myrmicinae). Insectes Soc 55:434-442. https://doi.org/10.1007/ s00040-008-1024-3

Hölldobler B, Wilson EO (1977) The number of queens: An important trait in ant evolution. Naturwissenschaften 64(1):8-15. https:// doi.org/10.1007/BF00439886

Hölldobler B, Wilson EO (1990) The ants. The Belknap Press of Harvard University Press, Cambridge, MA

Hughes WOH, Boomsma JJ (2004) Genetic diversity and disease resistance in leaf-cutting ant societies. Evolution 58:1251-1260. https://doi.org/10.1111/j.0014-3820.2004.tb01704.x

Hughes WOH, Boomsma JJ (2007) Genetic polymorphism in leafcutting ants is phenotypically plastic. Proc R Soc B Biol Sci 274:1625-1630. https://doi.org/10.1098/rspb.2007.0347

Hughes WOH, Oldroyd BP, Beekman M, Ratnieks FLW (2008a) Ancestral monogamy shows kin selection is key to the evolution of eusociality. Science 320:1213-1216. https://doi.org/10.1126/ science. 1156108

Hughes WOH, Ratnieks FLW, Oldroyd BP (2008b) Multiple paternity or multiple queens: two routes to greater intracolonial genetic diversity in the eusocial Hymenoptera. J Evol Biol 21:10901095. https://doi.org/10.1111/j.1420-9101.2008.01532.x

Hughes WOH, Sumner S, Van BS, Boomsma JJ (2003) Worker caste polymorphism has a genetic basis in Acromyrmex leaf-cutting ants. Proc Natl Acad Sci U S A 100:9394-9397. https://doi.org/ 10.1073/pnas.1633701100

Ingram KK (2002) Plasticity in queen number and social structure in the invasive Argentine ant (Linepithema humile). Evolution
56:2008-2016. https://doi.org/10.1554/0014-3820(2002) 056[2008:PIQNAS]2.0.CO;2

Johnson RA (2004) Colony founding by pleometrosis in the semiclaustral seed-harvester ant Pogonomyrmex californicus (Hymenoptera: Formicidae). Anim Behav 68(5):1189-1200. https://doi.org/ 10.1016/j.anbehav.2003.11.021

Jones OR, Wang J (2010) COLONY: A program for parentage and sibship inference from multilocus genotype data. Mol Ecol Resour 10:551-555. https://doi.org/10.1111/j.1755-0998.2009.02787.x

Julian GE, Fewell JH (2004) Genetic variation and task specialization in the desert leaf-cutter ant, Acromyrmex versicolor. Anim Behav 68:1-8. https://doi.org/10.1016/j.anbehav.2003.06.023

Kearse M, Moir R, Wilson A et al (2012) Geneious Basic: an integrated and extendable desktop software platform for the organization and analysis of sequence data. Bioinformatics 28:1647-1649. https://doi.org/10.1093/bioinformatics/bts199

Keller L (1995) Parasites, worker polymorphism, and queen number in social insects. Am Nat 145:842-847. https://doi.org/10.1086/ 285772

Keller L, Reeve HK (1994) Genetic variability, queen number, and polyandry in social Hymenoptera. Evolution 48:694-704. https:// doi.org/10.2307/2410479

Kellner K, Trindl A, Heinze J, D'Ettorre P (2007) Polygyny and polyandry in small ant societies. Mol Ecol 16:2363-2369. https://doi. org/10.1111/j.1365-294X.2007.03297.x

Kraus FB, Moritz RFA (2010) Extreme polyandry in social Hymenoptera: evolutionary causes and consequences for colony organisation. In: Kappeler P (ed) Animal Behaviour: Evolution and Mechanisms. Springer-Verlag, Berlin, Heidelberg, pp 413-439

Kraus FB, Neumann P, Van Praagh J, Moritz RFA (2004) Sperm limitation and the evolution of extreme polyandry in honeybees (Apis mellifera L.). Behav Ecol Sociobiol 55:494-501. https://doi.org/ 10.1007/s00265-003-0706-0

Kronauer DJC, Boomsma JJ (2007) Do army ant queens re-mate later in life? Insectes Soc 54:20-28. https://doi.org/10.1007/ s00040-007-0904-2

Kronauer DJC, Schoening C, Pedersen JS et al (2004) Extreme queen-mating frequency and colony fission in African army ants. Mol Ecol 13:2381-2388. https://doi.org/10.1111/j.1365294X.2004.02262.x

Kuzdzal-Fick JJ, Fox SA, Straussmann JE, Queller DC (2011) High relatedness is necessary and sufficient to maintain multicellularity in Dictyostelium. Science 334:1548-1551. https://doi. org/10.3334/ORNLDAAC/797

Leppänen J, Seppä P, Vepsäläinen K, Savolainen R (2015) Genetic divergence between the sympatric queen morphs of the ant Myrmica rubra. Mol Ecol 24:2463-2476. https://doi.org/10. 1111/mec. 13170

Lukas D, Clutton-Brock T (2012a) Life histories and the evolution of cooperative breeding in mammals. Proc R Soc B Biol Sci 279:4065-4070. https://doi.org/10.1098/rspb.2012.1433

Lukas D, Clutton-Brock T (2012b) Cooperative breeding and monogamy in mammalian societies. Proc R Soc B Biol Sci 279:21512156. https://doi.org/10.1098/rspb.2011.2468

Maynard Smith J (1977) Parental investment: a prospective analysis. Anim Behav 25:1-9. https://doi.org/10.1016/0003-3472(77) 90062-8

Mintzer AC (1987) Primary polygyny in the ant Atta texana: number and weight of females and colony foundation success in the laboratory. Insectes Soc 34:108-117. https://doi.org/10.1007/ BF02223829

Murakami T, Higashi S, Windsor D (2000) Mating frequency, colony size, polyethism and sex ratio in fungus growing ants (Attini). Behav Ecol Sociobiol 48:276-284. https://doi.org/10.1007/ s002650000243 
Nehring V, Dijkstra MB, Sumner S et al (2018) Reconstructing the relatedness of cooperatively breeding queens in the Panamanian leaf-cutting ant Acromyrmex echinatior (Hymenoptera: Formicidae). Myrmecological News 27:33-45

Nielsen R, Tarpy DR, Reeve HK (2003) Estimating effective paternity number in social insects and the effective number of alleles in a population. Mol Ecol 12:3157-3164. https://doi. org/10.1046/j.1365-294X.2003.01994.X

Nonacs P, Tobin JE (1992) Selfish larvae: development and the evolution of parasitic behavior in the Hymenoptera. Evolution 46:1605-1620. https://doi.org/10.2307/2410019

Nygaard S, Hu H, Li C et al (2016) Reciprocal genomic evolution in the ant-fungus agricultural symbiosis. Nat Commun 7:1-9. https://doi.org/10.1038/ncomms 12233

Oldroyd BP, Fewell JH (2007) Genetic diversity promotes homeostasis in insect colonies. Trends Ecol Evol 22:408-413. https:// doi.org/10.1016/j.tree.2007.06.001

Page RE Jr, Robinson GE, Fondrk MK (1989) Genetic specialists, kin recognition and nepotism in honey-bee colonies. Nature 338:576-579. https://doi.org/10.1038/338576a0

Pamilo P (1993) Polyandry and allele frequency differences between the sexes in the ant Formica aquilonia. Heredity 70:472-480. https://doi.org/10.1038/hdy.1993.69

Pamilo P, Crozier RH (1996) Reproductive skew simplified. Oikos 75:533-535

Pedersen JS, Boomsma JJ (1999a) Positive association of queen number and queen-mating frequency in Myrmica ants: a challenge to the genetic-variability hypotheses. Behav Ecol Sociobiol 45:185-193. https://doi.org/10.1007/s002650050552

Pedersen JS, Boomsma JJ (1999b) Multiple paternity in social Hymenoptera: estimating the effective mate number in singledouble mating populations. Mol Ecol 8:577-587. https://doi. org/10.1046/j.1365-294X.1999.00573.x

Pew J, Muir PH, Wang J, Frasier TR (2015) related: an R package for analysing pairwise relatedness from codominant molecular markers. Mol Ecol Resour 15:557-561. https://doi.org/10. 1111/1755-0998.12323

Purcell J, Pellissier L, Chapuisat M (2015) Social structure varies with elevation in an Alpine ant. Mol Ecol 24:498-507. https:// doi.org/10.1111/mec. 13042

Qian ZQ, Schlüns H, Schlick-Steiner BC et al (2011) Intraspecific support for the polygyny-vs.-polyandry hypothesis in the bulldog ant Myrmecia brevinoda. Mol Ecol 20:3681-3691. https:// doi.org/10.1111/j.1365-294X.2011.05195.x

Queller DC, Goodnight KF (1989) Estimating relatedness using genetic markers. Evolution 43:258-275. https://doi.org/10. $2307 / 2409206$

R Core Team (2021) R: a language and environment for statistical computing. R Foundation for Statistical Computing

Rabeling C (2020) Social parasitism. In: Starr C (ed) Encyclopedia of Social Insects. Springer, Cham, pp 838-858

Rabeling C, Bollazzi M, Bacci M et al (2014a) Development and characterization of twenty-two polymorphic microsatellite markers for the leafcutter ant, Acromyrmex lundii, utilizing Illumina sequencing. Conserv Genet Resour 6:319-322. https://doi.org/10.1007/s12686-013-0078-3

Rabeling C, Bollazzi M, Delabie JHC, et al (2018) Reconstructing the evolutionary history of leaf-cutting ants reveal multiple origins of inquiline social parasitism via sympatric speciation. In: XVIII International Conference of the Union for the Study of Social Insects. São Paulo, Brazil

Rabeling C, Cover SP, Johnson RA, Mueller UG (2007a) A review of the North American species of the fungus-gardening ant genus Trachymyrmex (Hymenoptera: Formicidae). Zootaxa 1664:1-53. https://doi.org/10.11646/zootaxa.1664.1.1
Rabeling C, Messer SJ, Lacau S et al (2019) Acromyrmex fowleri: a new inquiline social parasite species of leaf-cutting ants from South America, with a discussion of social parasite biogeography in the Neotropical region. Insectes Soc 66:435-451. https://doi.org/10.1007/s00040-019-00705-z

Rabeling C, Schultz TR, Bacci M, Bollazzi M (2015) Acromyrmex charruanus: a new inquiline social parasite species of leafcutting ants. Insectes Soc 62:335-349. https://doi.org/10.1007/ s00040-015-0406-6

Rabeling C, Schultz TR, Pierce NE, Bacci M (2014b) A social parasite evolved reproductive isolation from its fungus-growing ant host in sympatry. Curr Biol 24:2047-2052. https://doi.org/10. 1016/j.cub.2014.07.048

Rabeling C, Verhaagh M, Engels W (2007b) Comparative study of nest architecture and colony structure of the fungus-growing ants, Mycocepurus goeldii and M. smithii. J Insect Sci 7:1-13. https://doi.org/10.1673/031.007.4001

Ratnieks FLW, Boomsma JJ (1995) Facultative sex allocation by workers and the evolution of polyandry by queens in social Hymenoptera. Am Nat 145:969. https://doi.org/10.1086/ 285779

Reber A, Castella G, Christe P, Chapuisat M (2008) Experimentally increased group diversity improves disease resistance in an ant species. Ecol Lett 11:682-689. https://doi.org/10.1111/j. 1461-0248.2008.01177.x

Reeve HK, Ratnieks FLW (1993) Queen-queen conflicts in polygynous societies: mutual tolerance and reproductive skew. In: Keller L (ed) Queen number and sociality in insects. Oxford University Press, Oxford, pp 45-85

Rissing SW, Johnson RA, Pollock GB (1986) Natal nest distribution and pleometrosis in the desert leaf-cutter ant acromyrmex versicolor (Pergande) (Hymenoptera: Formicidae). Psyche: A Journal of Entomology 93(3-4):177-186. https://doi.org/10. $1155 / 1986 / 36205$

Rissing SW, Pollock GB, Higgins MR, Hagen RH, Smith DR (1989) Foraging specialization without relatedness or dominance among co-founding ant queens. Nature 338(6214):420-422. https://doi.org/10.1038/338420a0

Rubenstein DI, Wrangham RW (1986) Socioecology: origins and trends. In: Rubenstein DI, Wrangham RW (eds) Ecological aspects of social evolution. Princeton, NJ, pp 3-20

Savolainen R, Vepsäläinen K (2003) Sympatric speciation through intraspecific social parasitism. Proc Natl Acad Sci U S A 100:7169-7174. https://doi.org/10.1073/pnas.1036825100

Schmid-Hempel P, Crozier RH (1999) Ployandry versus polygyny versus parasites. Philos Trans R Soc B Biol Sci 354:507-515. https://doi.org/10.1098/rstb.1999.0401

Seeley TD, Tarpy DR (2007) Queen promiscuity lowers disease within honeybee colonies. Proc R Soc London B 274:67-72. https://doi.org/10.1098/rspb.2006.3702

Seppä P, Sundström L, Puntitila P (1995) Facultative polygyny and habitat succession in boreal ants. Biol J Linn Soc 56:533-551. https://doi.org/10.1016/0024-4066(95)90003-9

Solomon SE, Rabeling C, Sosa-Calvo J et al (2019) The molecular phylogenetics of Trachymyrmex Forel ants and their fungal cultivars provide insights into the origin and coevolutionary history of 'higher-attine' ant agriculture. Syst Entomol 44:939-956. https://doi.org/10.1111/syen.12370

Sosa-Calvo J, Schultz TR, Ješovnik A et al (2018) Evolution, systematics, and natural history of a new genus of cryptobiotic fungus-growing ants. Syst Entomol 43:549-567. https://doi. org/10.1111/syen.12289

Souza DJ, Della Lucia TMC, Lima ER (2005) Queen adoption in colonies of the leaf-cutting ant Acromyrmex subterraneus 
molestans (Hymenoptera: Formicidae). Behav. Proc. 70:62-68. https://doi.org/10.1016/j.beproc.2005.04.002

Souza DJ, Lino Neto J, Della Lucia TMC, Peternelli E (2004) Occurrence of polygyny in Acromyrmex subterraneus molestans Santschi 1925 (Hymenoptera: Formicidae). Ciência Rural 34:1611-1613. https://doi.org/10.1590/S0103-8478200400 0500045

Stanford CB (1998) The social behavior of chimpanzees and bonobos: empirical evidence and shifting assumptions. Curr Anthropol 39:399-420. https://doi.org/10.1086/204757

Strassmann J (2001) The rarity of multiple mating by females in the social Hymenoptera. Insectes Soc 48:1-13. https://doi.org/10. 1007/PL00001737

Stürup M, Nash DR, Hughes WOH, Boomsma JJ (2014) Sperm mixing in the polyandrous leaf-cutting ant Acromyrmex echinatior. Ecol Evol 4:3571-3582. https://doi.org/10.1002/ece3.1176

Tarpy DR (2003) Genetic diversity within honeybee colonies prevents severe infections and promotes colony growth. Proc $\mathrm{R}$ Soc London Ser B Biol Sci 270:99-103. https://doi.org/10. 1098/rspb.2002.2199

Trunzer B, Heinze J, Hölldobler B (1998) Cooperative colony founding and experimental primary polygyny in the ponerine ant Pachycondyla villosa. Insectes Sociaux 45(3):267-276. https:// doi.org/10.1007/s000400050087

Trontti K, Thurin N, Sundström L, Aron S (2007) Mating for convenience or genetic diversity? Mating patterns in the polygynous ant Plagiolepis pygmaea. Behav Ecol 18:298-303. https://doi. org/10.1093/beheco/arl083

Villesen P, Gertsch PJ, Frydenberg J et al (1999) Evolutionary transition from single to multiple mating in fungus-growing ants. Mol Ecol 8:1819-1825. https://doi.org/10.1046/j.1365-294X. 1999.00767.x

Villesen P, Murakami T, Schultz TR, Boomsma JJ (2002) Identifying the transition between single and multiple mating of queens in fungus-growing ants. Proc R Soc B 269:1541-1548. https:// doi.org/10.1098/rspb.2002.2044

Waddington SJ, Santorelli LA, Ryan FR, Hughes WOH (2010) Genetic polyethism in leaf-cutting ants. Behav Ecol 128:11651169. https://doi.org/10.1093/beheco/arq128

West-Eberhard MJ (1975) The evolution of social behavior by kin selection. Q Rev Biol 50:1-33. https://doi.org/10.1086/408298

West SA, Gardner A (2010) Altruism, spite, and greenbeards. Science 327:1341-1344. https://doi.org/10.1126/science.1178332

Wickham H (2009) ggplot2: elegant graphics for data analysis. Springer-Verlag, New York

Wilson EO (1975) Some central problems of sociobiology. Soc Sci Inf 14:5-18. https://doi.org/10.1177/053901847501400601

Publisher's note Springer Nature remains neutral with regard to jurisdictional claims in published maps and institutional affiliations.

\title{
Authors and Affiliations
}

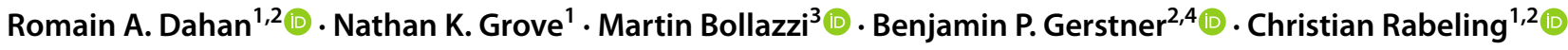 \\ Romain A. Dahan \\ romain.a.dahan@gmail.com \\ $\triangle$ Christian Rabeling \\ crabeling@gmail.com \\ 1 School of Life Sciences, Arizona State University, Tempe, \\ AZ, USA \\ 2 Department of Biology, University of Rochester, Rochester, \\ NY, USA \\ 3 Facultad de Agronomía, Universidad de La República, \\ Montevideo, Uruguay \\ 4 Department of Biology, University of New Mexico, \\ Albuquerque, NM, USA
}

